\title{
PROTOTYPE OF A MICRO MONITORING STATION WITH REMOTE TORRENTIAL FLOOD ALERTS
}

\author{
Enes Šakrak', \\ Miloš Dobrojević2* \\ ${ }^{1}$ Government of Brčko District of B\&H, \\ $\mathrm{B} \& \mathrm{H}$ \\ ${ }^{2}$ Faculty of Technical Sciences, \\ Singidunum University, \\ Belgrade, Serbia
}

\begin{abstract}
:
The Internet of Things (IoT) enables the gathering and exchange of data between a multitude of electronic devices. Collected data then can be centrally stored and analyzed, and furthermore, the obtained results can be used for processes automation and timely decision making. These basic principles of IoT can also be applied upon an early warning system for torrential floods, with the aim of protecting people, livestock and property. The basic building block of this system is an automated micro monitoring station (AMMS) based on an Arduino microcontroller with sensors for reading of targeted physical quantities and with a power block allowing autonomous functioning. The AMMS prototype presented in this paper possesses compact dimensions, simple enough and modular architecture, reasonable production price, and thus may prove to be an effective tool for monitoring of torrential streams, which usually occur in remote and inaccessible mountainous areas where standard monitoring stations of the official Hydro-meteorological Institute cannot be set up due to technical or economic reasons.
\end{abstract}

Keywords:

Internet of Things, Automatic Monitoring Stations, Torrential Floods, Early Warning System, Arduino Flood Detection

\section{INTRODUCTION}

At the territory of the Western Balkans (WB), representing states formed by the disintegration of the former Yugoslavia and Albania, floods occur on regular basis as a result of seasonal snow melting and heavy rains, most damage causing to agriculture, roads and infrastructure. Due to the characteristic relief of the WB, torrential floods as short-lived but turbulent events originating in the upper parts of the river basins are becoming increasingly frequent, causing significant material damage and loss of lives $[1,2,3]$.

The hydrological situation is monitored by the Hydro-meteorological Institutes on all major watercourses, Figure 1. However, due to technical and economic limitations, the floods monitoring network does not cover remote mountainous areas prone to sudden torrential waters, as may be evident in Figure 2.
Correspondence:

Miloš Dobrojević

e-mail:

mdobrojevic@singidunum.ac.rs 
Over the last 20 years, the consequences of floods in the region have been intensively monitored and analyzed, with a special focus on the catastrophic events of 2014, Figures 3 and 4, on the basis of which each country developed appropriate flood risk maps.

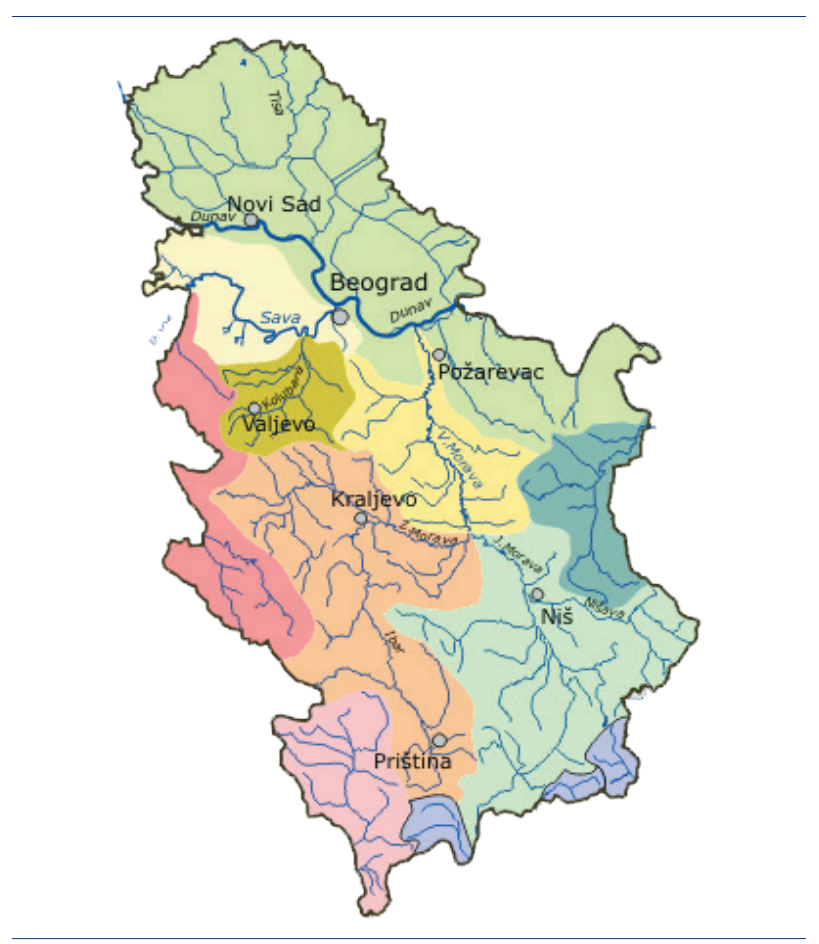

Fig. 1. River basins network in Serbia [4]

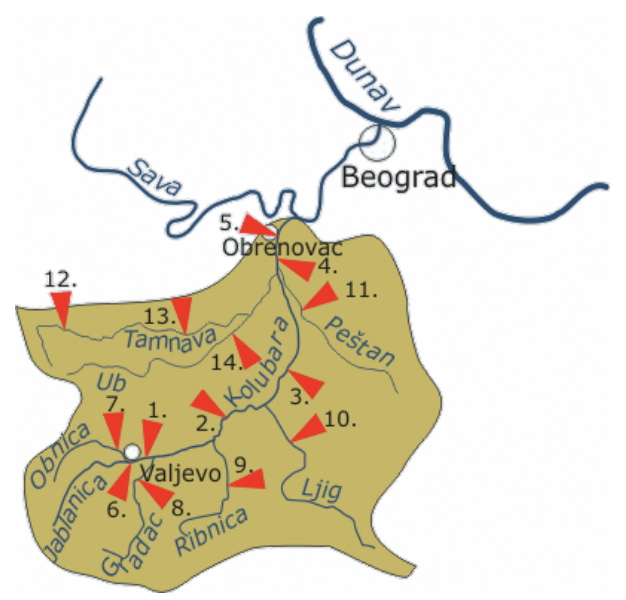

Fig. 2. Surface water station network The Kolubara river basin [5]

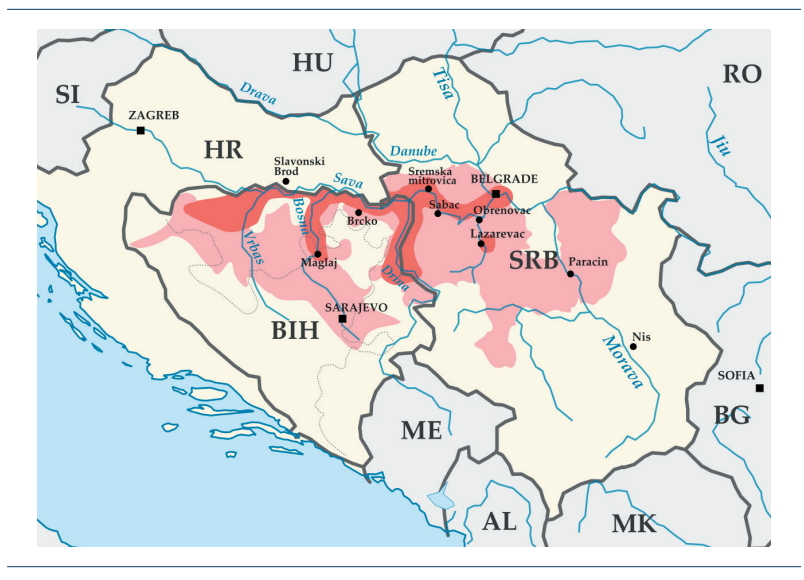

Fig. 3. Floods in the West Balkans, affected teritories in 2014 [6]

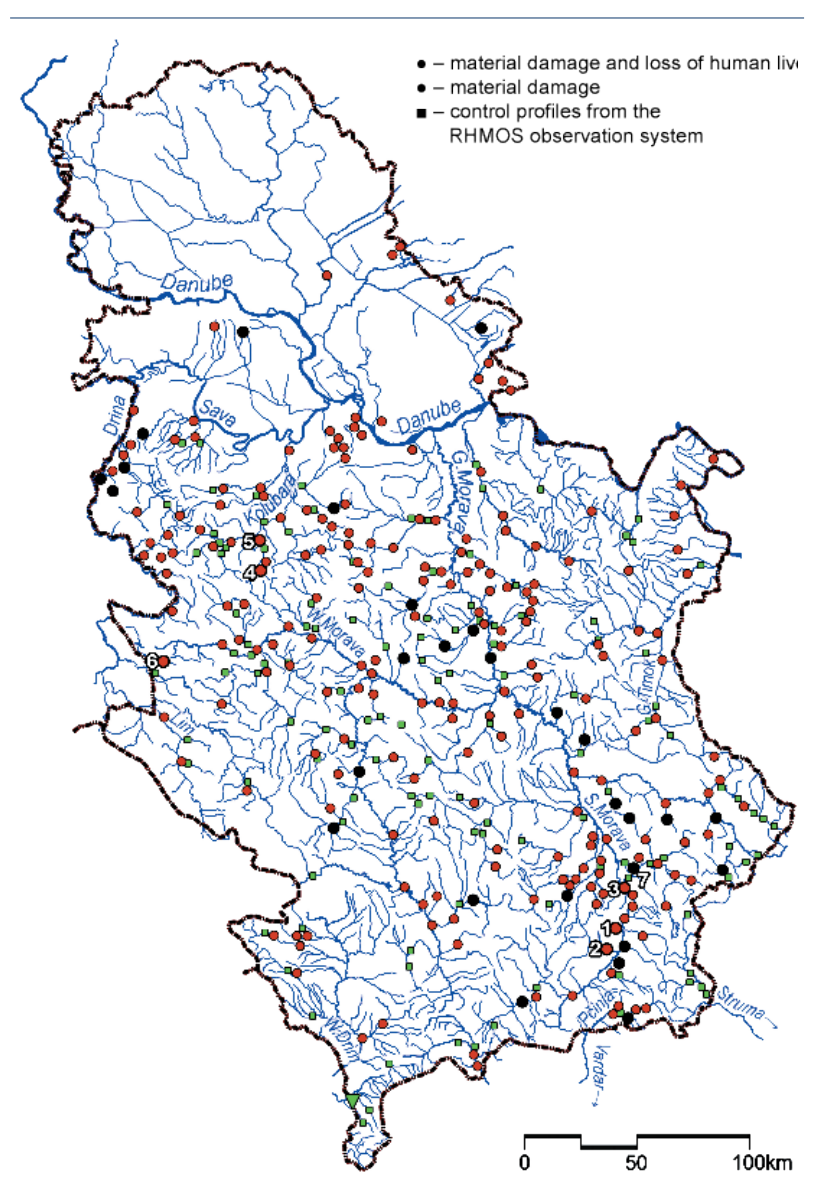

Fig. 4. Catastrophic torrential flood events in Serbia (1950-2010) [7]

\section{USE OF IOT IN THE COURSE OF FLOODS}

The Internet of Things (IoT) enables the gathering of data and their exchange between a multitude of sensors, electronic devices and applications. A large amount of data collected this way, can subsequently be analyzed 
and used to automate day-to-day activities, including decision-making processes [8]. Eventually, integrated systems consisting of computers, microcontrollers, sensors and specialized software can make life easier for an ordinary person, empowering remote control of household appliances (e.g. heating and air conditioning, security systems and alarms, home automation), automation of agricultural production and the like. The application of such technology requires well-developed communication infrastructure and good coverage of the GSM signal, which is a prerequisite already met by all the countries in the Western Balkans.

The same technology can be applied in terms of protection of the population, facilities and infrastructure from natural disasters by observing the critical locations and remotely reading relevant parameters. The collected data is then analyzed, and in case of exceeding the pre-set limits, alarm activation and other actions can be taken.

Although this problem is in the focus of many researchers, primarily the possibility of use of microcontrollers, such as the Arduino, to monitor water levels [9] or to perform video surveillance of flooded areas [10], commercial systems available on the market are mostly intended for use in individual households as basement flood detectors.

\section{ARDUINO BASED MICRO MONITORING STATION}

Generally, the basic tasks of a flood protection system are:

- monitoring of water level and other critical parameters on the given perimeter

- data processing and comparison with the preset boundary values

- activation of alarm signal, if necessary

The main advantages of the Arduino microcontroller as a base platform for projects of this type are its affordability, modularity and a number of sensors making possible reading of the appropriate parameters and their transmission via wireless network (WiFi, XBee) or via the mobile Internet.

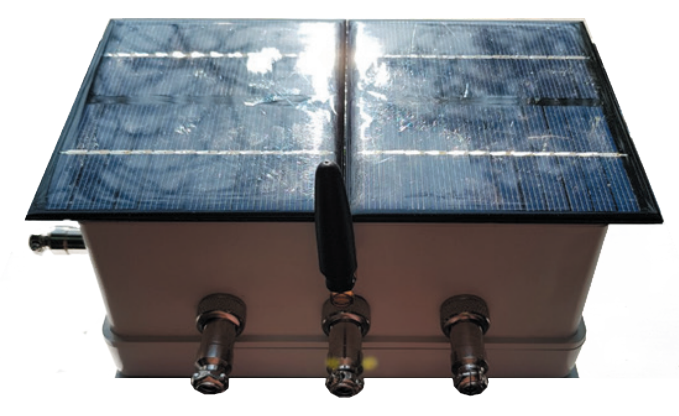

Fig. 5. Automated Micro Monitoring Station
This paper presents a prototype of Automated Micro Monitoring Station (AMMS), based on an Arduino microcontroller, Figure 5, capable of reading the local meteorological parameters, water level and sensing ground oscillations. A limited analysis of collected data can be performed and compared with the predefined values, and in case of exceeding the preset limits, the warning can be sent in the form of a Short Message Service (SMS) message to the predefined cell phone number(s). The station is autonomous in operation thanks to built-in solar cells and batteries. All components are placed into small waterproof housing, which makes the measuring station suitable for use in remote mountainous areas, in locations that are not covered by the network of measuring stations belonging to the Hydro-meteorological Institute.

Proposed AMMS can work as a standalone unit for early warning, for example protecting a village or smaller settlement with a single torrential stream. In such scenario, custom software embedded into Arduino microcontroller evaluates readings, and in case of meeting the critical parameters, sends SMS warning to predefined phone number.

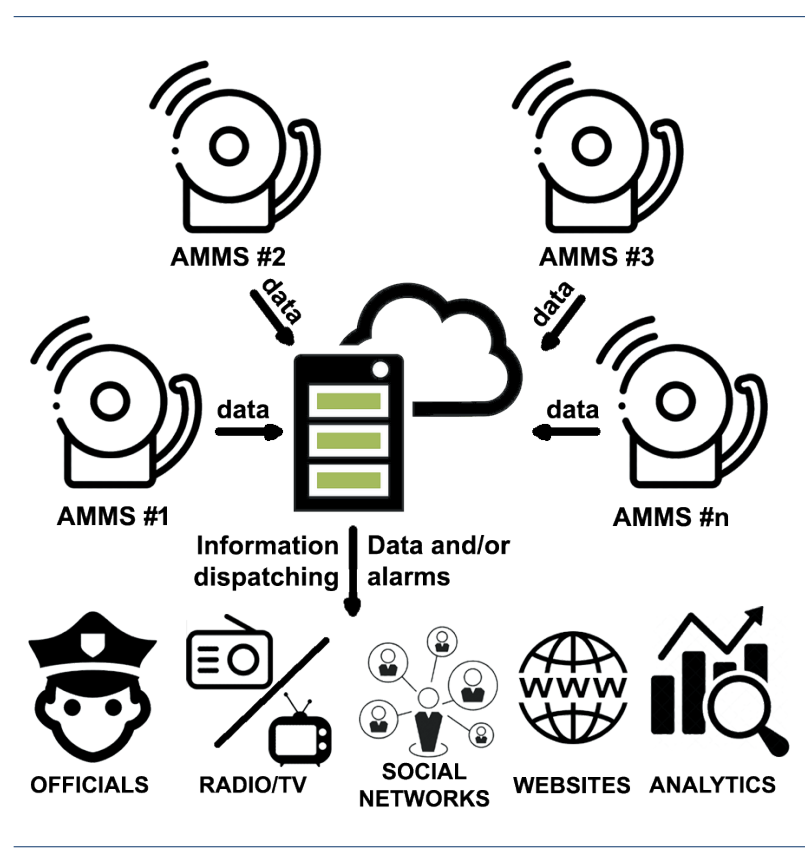

Fig. 6. Multi-AMMS early warning system, schematic representation

Two or more AMMSs may form an early warning system covering one or more torrents, or larger critical area, Figure 6. How many AMMSs the system will contain depends on the size of the observed area, the configuration of the terrain and the complexity of the river basin. In that case, the data is transferred to the central server where it gets stored and processed by custom developed web application which is tasked to perform the analytics and, if necessary, to trigger an alarm signal. 


\section{Hardware components of the AMMS}

Figure 7 shows an open AMMS housing with system components. The basic component of AMMS is an Arduino microcontroller with the task of reading data from sensors. An ultrasonic sensor is used to read water levels, while a combined temperature sensor, in addition to temperature, reads air pressure and relative humidity aswell. Vibration sensor module can be included into package too, in order to provide data indicating landslides. Finally, the AMMS also contains a GSM module used for messages and data dispatching.

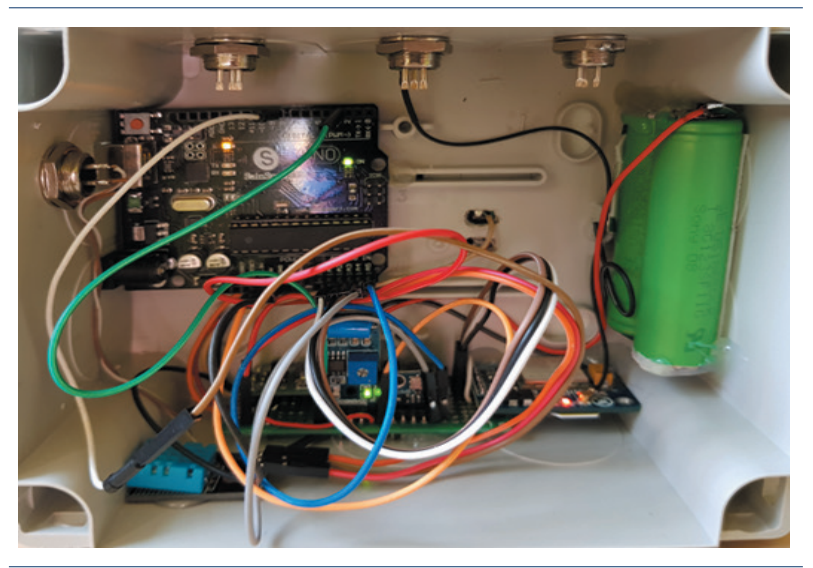

Fig. 7. AMMS, electronic components [11]

Electric power is provided by two Li-Ion battery cells charged by a pair of solar cells, making possible autonomous operation of the AMMS. Due to its light weight and modest dimensions, the AMMS can be easily transported and placed in inaccessible terrain.

In order to conserve power, AMMS is by default in the state of hibernation. The Arduino board wakes up from hibernation every 15 minutes, reads sensors, performs pre-programmed data analysis, sends message or data, and then returns to hibernation.

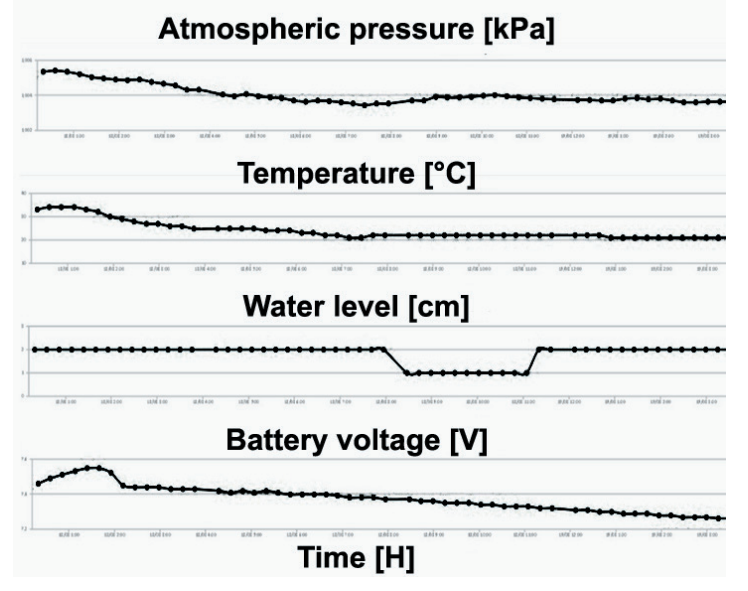

Fig. 8. AMMS, test sensor readings over 12-hour time span [11]

\section{DATA MONITORING, DISPATCHING AND ANALYTICS}

The AMMS via sensors takes the readings of physical quantities in the immediate environment, Figure 8, and in case of exceeding the preset boundary values, it can take preventive measures. When operating as a standalone unit, the AMMS may send alert messages to predefined cell phone numbers, Figure 9.

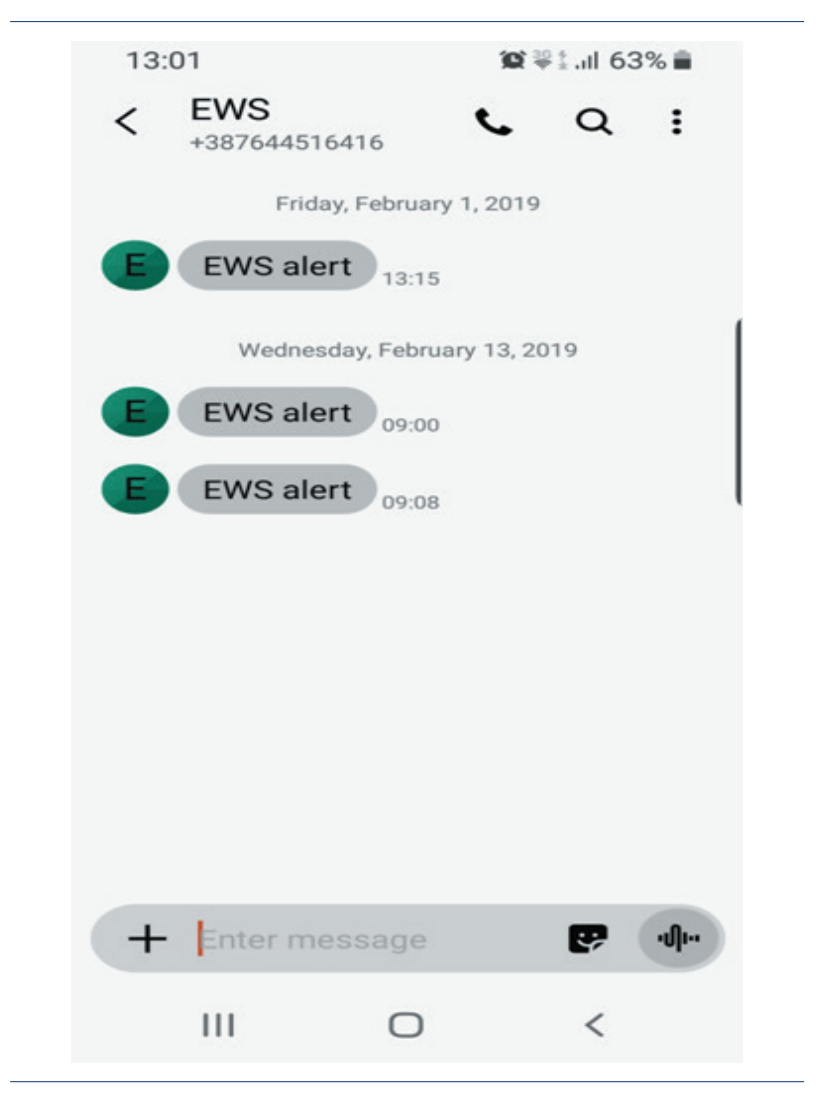

Fig. 9.Text message alert [11]

In scenario when a territory or an entire region is covered by a network of AMMSs, each AMMS converts the collected data into JSON format and sends file via mobile internet to the central web server, where data gets stored in the SQL database for further analysis.

Data control and analytical tasks are performed by a web application written in the PHP programming language, available on the public Internet domain. Processed data afterwards can be distributed publicly or through protected channels, in accordance with the level of access to information that a particular person carries within the flood defense system.

Users can access the application with various electronic devices, such as desktops, laptops, tablets or smart phones. 
In case of imminent danger, the web application can trigger alarm signal or broadcast alerts to a wider public through the social networks, radio or TV stations.

\section{CONCLUSION}

This paper presents a prototype of an automated micro monitoring station that can be used as a standalone unit, or as a component of a larger system, with the aim of early detection of torrential flood hazards.

Due to its modest overall dimensions, simplified modular architecture, low power consumption and affordable price, the AMMS is easy to produce, transport and deploy on inaccessible terrains, where it becomes immediately operational.

Each unit contains Li-Ion batteries and solar cells allowing autonomous operation. Additional power conservation and uninterrupted operation throughout the day, in all weather conditions and seasons was achieved by setting the AMMS into hibernation by default, with periodic short term activation at regular time intervals.

In the current phase of prototype optimization, the built-in software is capable of recognizing the state of emergency in a given time span, upon which it sends warning to a predefined cell phone number.

In scenarios with multiple AMMSs operating within the system, the information is dispatched to web server for storage, further analytics, and if necessary, alert triggering.

In case of severe weather, GSM networks occasionally may become inoperative, which may affect the operation of the proposed early warning system. Data transmission in such conditions may render incomplete and / or delayed, which in turn requires additional research in terms of evaluation of electronic components and applying alternative methods of information transmission in order to improve system stability.

\section{REFERENCES}

[1] S. Pantelić-Miralem, "Odbrana od poplava", Inženjerska komora Srbije, 2015.

[2] V. Kolarov, M. Babić-Mladenović, "Podaci za izradu preliminarne procene rizika od poplava na teritoriji Republike Srbije", Vodoprivreda, vol. 42(1-3), 2010, pp. 79-86.

[3] "Joint management of flood risks", Romania-Republic of Serbia IPA Cross-border Cooperation Programme, 2016. Available: http://www.floodrisks.
rs/uploads/dokumenta/5875e2f479432Vol_4_SR _tekst_def.pdf

[4] "Distribution of stations on regional stations and on the basins of major rivers", Republic Hydrometeorological Service of Serbia. Available: http://www. hidmet.gov.rs/eng/hidrologija/povrsinske/index. php

[5] "Surface water station network - The Kolubara basin", Republic Hydrometeorological Service of Serbia. Available: http:// www.hidmet.gov.rs/eng/ hidrologija/povrsinske/index.php

[6] K. Glock et al., "Report on natural disasters in the Western Balkans", Development of master curricula for natural disasters risk management in Western Balkan countries, Project number 573806-EPP1-2016-1-RS-EPPKA2-CBHE-JP, 2017.

[7] R. Ristić, S. Kostadinov, B. Abolmasov et al., "Torrential floods and town and country planning in Serbia", Natural Hazards and Earth System Sciences, vol. 12, 2012, pp. 23-35

[8] K. Schwab, "The Fourth Industrial Revolution", World Economic Forum, 2016, ISBN-10: 1944835016

[9] V. Vunabandi, R. Matsunaga, S. Markon and N. Willy, "Flood sensing framework by Arduino and Wireless Sensor Network in Rural-Rwanda," 2015 IEEE/ACIS 16th International Conference on Software Engineering, Artificial Intelligence, Networking and Parallel/Distributed Computing (SNPD), Takamatsu, 2015, pp. 1-6, doi: 10.1109/ SNPD.2015.7176210.

[10] R.A. Santos, R.R. Guadana, "Flood detector system using Arduino", International Journal of Management and Applied Science, vol. 2(7), 2016, pp. 286-290

[11] E. Šakrak, M. Dobrojević, S.A. Sedmak, "IoT based Early Warning System for Torrential Floods", FME Transactions, vol. 48(3), 2020, pp. 511-515, doi: $10.5937 /$ fme2003511S. 